Article

\title{
Study on the Relations of Supply Chain Digitization, Flexibility and Sustainable Development-A Moderated Multiple Mediation Model
}

\author{
Qian Zhou ${ }^{1,2, *}$ and Shuxiang Wang ${ }^{1}$ \\ 1 School of Economics and Management, Beijing Jiaotong University, Beijing 100044, China; \\ shxwang@bjtu.edu.cn \\ 2 School of Business Administration, Shandong Women's University, Jinan 250300, China \\ * Correspondence: sallyzhou0718@163.com; Tel.: +86-156-6575-2787
}

Citation: Zhou, Q.; Wang, S. Study on the Relations of Supply Chain Digitization, Flexibility and Sustainable DevelopmentA Moderated Multiple Mediation Model. Sustainability 2021, 13, 10043. https://doi.org/10.3390/su131810043

Academic Editors: Fengxiang Qiao and Dong $\mathrm{Mu}$

Received: 19 July 2021

Accepted: 1 September 2021

Published: 8 September 2021

Publisher's Note: MDPI stays neutral with regard to jurisdictional claims in published maps and institutional affiliations.

Copyright: () 2021 by the authors. Licensee MDPI, Basel, Switzerland. This article is an open access article distributed under the terms and conditions of the Creative Commons Attribution (CC BY) license (https:// creativecommons.org/licenses/by/ $4.0 /)$.

\begin{abstract}
In the face of an external environment featuring a high level of risk, multiple changes, and high uncertainty, the supply chain's emergency replenishment, collaborative management, regulation of organic commodity, and low-cost rapid response will promote its' sustainable growth and development, which is necessary for today's economic development. The digitization and flexibility of the supply chain are of great value in obtaining the sustainable development of the supply chain. When dealing with an uncertain environment and market risk, current supply chain flexibility not only functions through its internal organizational flexibility, but also through collaborative creation and an extended supply chain network which will proactively form a replenishment supply sub-chain driven by the need for change responsiveness. This article constructs an associated model consisting of digitization, supply chain flexibility, and sustainability using an empirical analysis method to explore the implicit correlation of these factors. The analysis results of the mediating effect model show that both digitization and flexibility have significant positive effects on the sustainable development of the supply chain. Collaborative knowledge creation and supply chain flexibility play multiple mediating roles while market uncertainty positively moderates the impact of supply chain flexibility on supply chain sustainable development.
\end{abstract}

Keywords: digitization; supply chain flexibility; collaborative knowledge creation; supply chain sustainability performance; moderated mediation effect

\section{Introduction}

With the increasingly complicated social labor division and uncertain market environment, enterprises are bearing increased pressure caused by uncertain factors [1]. Higher requirements than before are being placed on the rapid, efficient response and coordinated disposal capability of the supply chain. The COVID-19 pandemic that broke out in early 2020 is still spreading, which has brought a huge challenge to the global supply chain. Many enterprises around the world are still facing the difficulties of labor shortage, transportation disruption, and supply chain disruption [2].

According to the operating data of micro, small, and medium enterprises in China (including information regarding operating revenue and the number of active companies) collected by the Internet Finance Laboratory, Pudaokou School of Finance of Tsinghua University from 1 January 2019 to 15 March 2020, with a total of 240,446 pieces of data, the number of enterprises with business data records in a single day reached 670,000; the maximum daily business volume was about 91.54 billion yuan, with an average of 35.12 billion yuan; the annual total business transaction record was 12.8 trillion yuan, accounting for $12.9 \%$ of the national GDP of China in 2019. Therefore, these data can provide a snapshot of the impact of COVID-19 on the operations of small and mediumsized enterprises in China. Figure 1 shows the total revenue of enterprises and active 
enterprise numbers in different months from Year 2019-2020. Figure 2 shows the difference comparison of total revenue of the enterprises between Year 2019 and 2020; while Figure 3 shows the difference between numbers of active enterprises per day of two years.
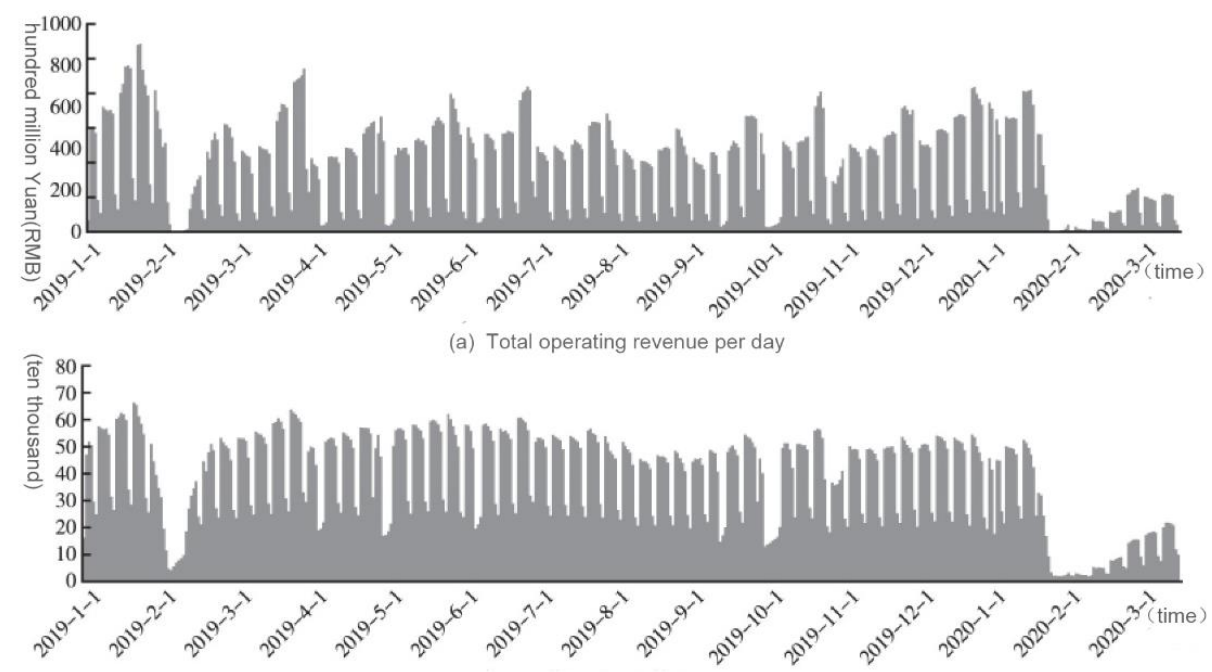

(b) Number of active businesses per day

Figure 1. (a) COVID-19's Effect on Enterprise Total Operating Revenue; (b) COVID-19's Effect on Number of Active Business. Refer to "Recovery of Small, Medium and Micro Economies under the Epidemic situation-Analysis and Research Report Based on Operation Data of Small, Medium and Micro Enterprises of a million magnitude"jointly released by Daokou Jinke.

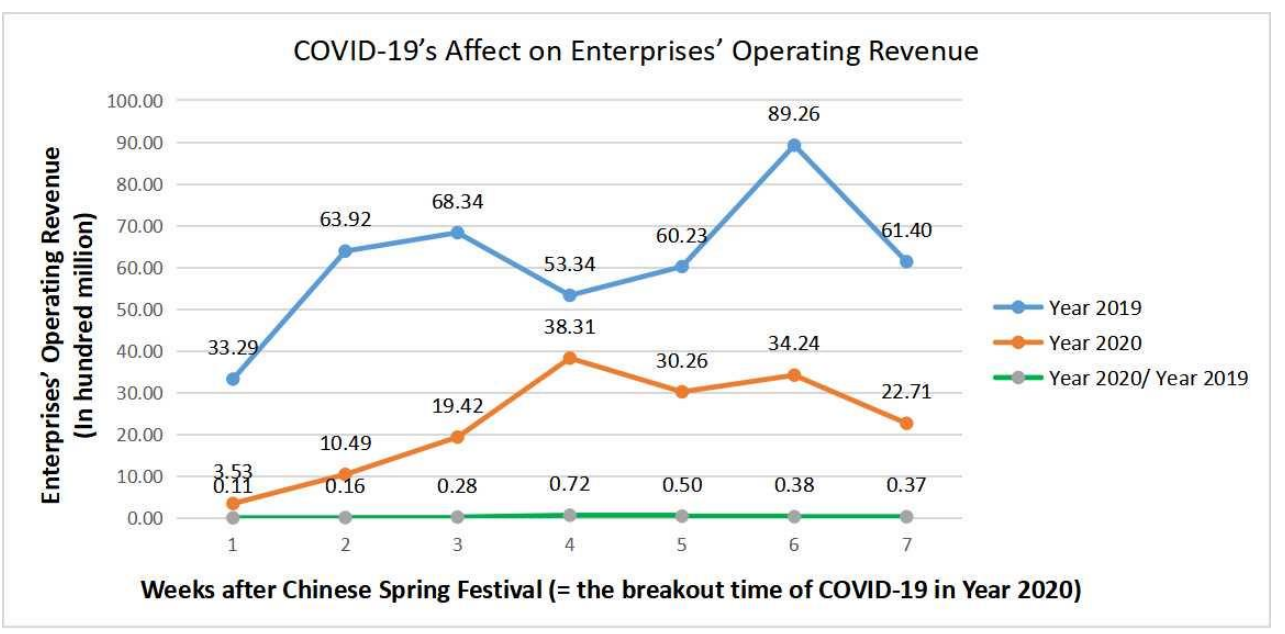

Figure 2. COVID-19's Effect on Enterprises' Operating Revenue.

With the globalization of the economy, the impact of the epidemic in one region can have a much more global impact. The economic and social destruction brought about will lead to a chain reaction. To reduce the economic and social destruction caused by elevated risk and high uncertainty, the sustainable operation of a supply chain has become particularly crucial nowadays. Similar points of view can be seen in a large quantity of research. For instance, Choi, T.Y. et al. (2020) argue that a sustainable supply chain not only promotes the economic development of enterprises, but is also crucial to developing the economy in a green way without sacrificing the environment or widespread social benefits [3]. Chowdhury and Quaddus (2021) further claim that a sustainable supply chain is essential, since sustainability encourages businesses to frame decisions regarding environmental, social, and human impact for the long-term, rather than short-term gains, such as immediate profit or loss [4]. Moreover, a sustainable supply chain was verified to be beneficial for market performance improvement [5]. 


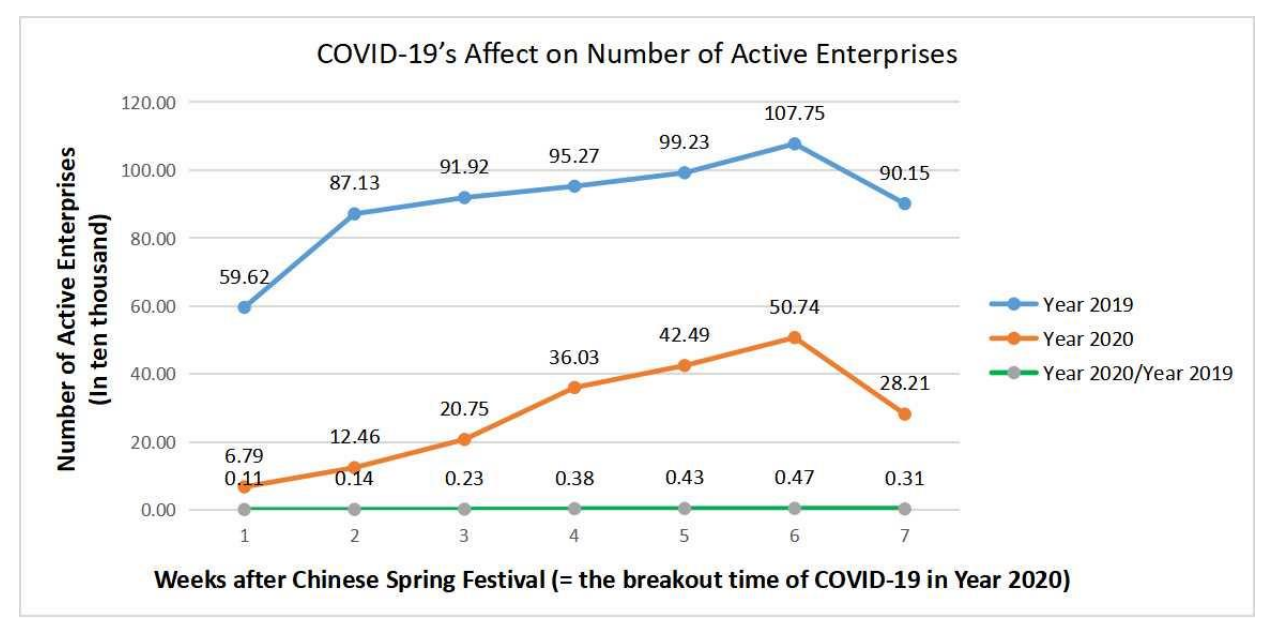

Figure 3. COVID-19's Effect on the Number of Active Enterprises.

The concept of sustainability broadens supply chain management to a wider and more integrated perspective rather than a uni-dimensional and dichotomous view. It extends environmental and economic concerns to the upstream and downstream entrepreneurial members of the supply chain [6,7]. Numerous factors in the supply chain can be involved with environmental protection as well as people's well-being. As to the supply chain structure, Guojun Ji et al. (2014) summarized that many environmental impact-reduction strategies can be simultaneously adopted in production, distribution, and use and disposal phases of the supply chain (i.e., the removal of toxic substances, the improvement of the accuracy of demand forecasts, and the adoption of cross-docking and comprehensive take-back networks). [8]. Not only can a sustainable supply chain make contributions to society, but it is also beneficial to supply chain enterprises. Sustainable development is one of the trending strategies to optimize total system profit for any supply chain system [9]. For maintaining the relationship between financial development and social responsibilities, a sustainable supply chain was essential in any industry to yield an enterprise's competitiveness, economic benefits, and better corporate social responsibility [10].

In the current study, a sustainable supply chain model is developed under the consideration of economic, environmental, and social benefits along with a digitization strategy, making the system more sustainable compared to the traditional one. The impact of digital technologies on economic and environmental performance in the context of industry 4.0 cannot be ignored. Digital technologies such as the Internet of Things, cloud computing, and big data analytics enable companies to adopt data-driven strategies and collect data to make the best possible decisions [11] and to improve the vertically and horizontally integrated supply chain system [12]. During the pandemic, the need for digitization further arises to look for sustainable solutions for the hybrid mode of operations and combat the crisis due to lack of resources. To overcome the ripple effect of a pandemic on supply chains, such as cost uncertainty, risk, and vulnerability, the supply chain needs to be smart and facilitated with technology-driven infrastructures that incorporate information flow into the supply chain processes [13]. Emerging tools, big data analytics, advanced robotics, decentralised agent-driven control, tracking, and tracing technologies all play an import role in increasing the supply chain's anti-risk ability [14].

Research has verified that the utilization of digital technologies in supply chain operations is necessary and crucial for building a sustainable supply chain; however, in what ways the supply chain digitization will affect the supply chain sustainability is still understudied in the literature. Are there any other factors that will jointly affect the supply chain's sustainability performance? According to Sarkis et al. (2020), a sustainable supply chain must learn to build flexible, innovative, collaborative process management in order to timely work out solutions for uncertainty problems, and effectively reduce the damage after the occurrence of risk [15]. Ramanathan et al. (2012) proved that the 
impact of collaborative planning, collaborative decision making of supply chain partners, and collaborative execution of all supply chain processes will make a positive impact on the success of supply chains [16]. Therefore, the concept of collaboration could be helpful for the supply chain's sustainability performance. Based on the concept of collaboration, the internal and external knowledge transfer and creation activities among the supply chain are proven to be crucial factors, able to create the collaborative process executions as well as supply chain flexibility $[10,17]$. Therefore, the collaborative knowledge creation activities seem to have a potential positive effect on the supply chain's sustainability performance.

Besides that, many research results have also proven that flexibility is another important factor that enables enterprises to better cope with the uncertain environment and recover quickly from the damage $[18,19]$. An excellent supply chain unit organization should learn to make use of flexible, innovative, and collaborative process management to increase risk prevention, prepare solutions for uncertain problems in time, and effectively reduce the damage caused by risks [15]. Until now, most research has focused on the internal organization flexibility within member enterprises in one supply chain, with little research extending its views to the external flexibility between different supply chains. In this article, the concept of flexibility of the supply chain is supplemented on the previous research results, claiming that the supply chain should also be an open, self-generative, and developmentally intelligent network, which continuously absorbs beneficial nutrition from the outside to improve itself, and continuously improves the rapid response and effective disposal ability of uncertain demand. The concept of flexibility we endorse not only means to adapt to challenges, to recover the usual status, but also cares more about self-improvement and self-generation through the intelligent supply chain network and tries to find an innovative way to cope with difficulties. This can be a new perspective to explain why flexibility is crucial to form a sustainable supply chain.

As seen from the above Table 1, different researchers have developed several supply chain models under the consideration of either digitization or flexibility, however, an associated model under the consideration of collaboration and market uncertainty, where market uncertainty being treated as a moderator, has not been put forward in this field. This article is trying to build a new associated model to fulfill the gap. Besides, this study supplements a new element, the self-generative and self-replenishment supply chain network, into the explanation of supply chain flexibility. A self-generative and selfreplenishment supply chain network will help to innovate new adaptations and response methods to uncertainties. The novelty in the literature compared to the existing literature is summarized in Table 1. The relationship between the digitization, supply chain flexibility, and supply chain sustainability has not been fully discussed and this article will make an in-depth analysis of how these parameters will affect the sustainability performance of the supply chain.

Table 1. Contributions of previous authors.

\begin{tabular}{|c|c|c|c|c|c|}
\hline Author(s) & Digitization & $\begin{array}{c}\text { Collaborative } \\
\text { Knowledge Creation }\end{array}$ & $\begin{array}{l}\text { Supply Chain } \\
\text { Flexibility }\end{array}$ & $\begin{array}{l}\text { Supply Chain } \\
\text { Sustainability }\end{array}$ & $\begin{array}{c}\text { Market } \\
\text { Uncertainty }\end{array}$ \\
\hline Li Y. et al. (2020) & $\checkmark$ & & & $\checkmark$ & \\
\hline Frank et al. (2019) & $\checkmark$ & & & $\checkmark$ & \\
\hline Ivanov et al. (2019) & $\checkmark$ & $\checkmark$ & & & \\
\hline Ben-Daya et al. (2019) & $\checkmark$ & & $\checkmark$ & & \\
\hline Sarkis et al. (2020) & & $\checkmark$ & $\checkmark$ & $\checkmark$ & $\checkmark$ \\
\hline Ramanathan et al. (2014) & & $\checkmark$ & & $\checkmark$ & \\
\hline Blome et al. (2014); & & & & & \\
\hline Chowdhury et al. (2021) & & 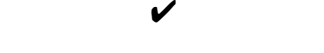 & $\checkmark$ & & \\
\hline $\begin{array}{l}\text { Sreedevi et al. (2017); } \\
\text { Blome et al. (2015) }\end{array}$ & & & $\checkmark$ & & $\checkmark$ \\
\hline Samudi P. et al. (2017) & & & $\checkmark$ & $\checkmark$ & \\
\hline Chang, A.Y. (2012) & & & $\checkmark$ & & $\checkmark$ \\
\hline This Study & $\checkmark$ & $\checkmark$ & $\checkmark$ & $\checkmark$ & $\checkmark$ \\
\hline
\end{tabular}


The existing research related to this field is described in the next section, whereas the assumptions and conceptual model are provided in Section 2. Section 3 contains the explanation of the research samples' choices and research methods used. In Section 4, statistics analysis of research sample, reliability and validity of the questionnaire, model fitness of the conceptual model, and correlation between factors are conducted to verify the correctness of the preliminary model; SME and Bootstrapping were conducted to show the coefficients and significance of each mediation and moderation effect pathway; the hierarchical regression method was used to check critical parameter's sensitivity, from which we can clearly what percentage of change in independent parameter value will cause $1 \%$ of change in the dependent parameter value with none-critical factors controlled. In other words, the partial coefficients of critical parameters can reflect the influence strength toward the dependent parameter, which-to some extent-displays the parameter's sensitivity. Section 5 contains the research conclusion and managerial implication. Finally, some research limitations and future extensions are provided in Section 6.

\section{Literature Review and Research Hypothesis}

\subsection{Literature Review of Supply Chain Flexibility}

Slack proposed the concept of supply chain flexibility for the first time, believing that it is the ability to respond to customer needs in a timely manner [20]. Li G. et al. believe that supply chain flexibility refers to resource sharing, business integration and optimization, and process collaboration among member enterprises in the supply chain in order to finally achieve the goal of meeting customer needs at a low cost [21]. Although the academic community has not reached a consensus on the definition of supply chain flexibility, scholars generally believe that supply chain flexibility is the ability to respond to uncertainty and meet customer expectations [22,23]. Supply chain flexibility is an important embodiment of an enterprise's dynamic capability, and it positively improves the recovery ability of the supply chain, thus further improving the competitiveness of the enterprise. In a complex and volatile market, enterprises urgently need to improve supply chain flexibility to reduce the possible losses caused by environmental uncertainties [24].

Some scholars have measured and evaluated supply chain flexibility from different dimensions. Ehap et al. measured it from two aspects: production flexibility and distribution flexibility [25]. Vokurka et al. believe that supply chain flexibility can be measured from product flexibility, output flexibility, and variety flexibility [26]. Meng J. et al. (2007) divided supply chain flexibility into product flexibility, output flexibility, capital flexibility, and information flexibility [27]. Boone et al. defined the concept of mitigating ability from two aspects: early warning ability and recovery ability [28]; early warning capability refers to detecting disruptions in the supply chain in advance and sharing this information with other member enterprises. Recovery ability refers to the supply chain's recovery to the expected operation level through the coordination of supply chain resources.

On the basis of prior research results, this article will evaluate supply chain flexibility from the following aspects. Firstly, 'enterprise supply chain's early warning system (EWS)' is aimed to predict and identify important trends as soon as possible by digital and technical means; secondly, 'supply chain structure flexibility' refers to enterprises' adaptability in adjusting the supply chain basic structure according to the long-term fundamental change of the market environment; thirdly, 'supply chain responsiveness' refers to the ability of an enterprise to quickly respond to the short-term and temporary changes; fourthly, a supply chain of high flexibility also means to 'self-generate, self-replenish, and proactively develop through collaboration of the supply chain network.'

\subsection{Digitization and Supply Chain Flexibility}

In recent years, many scholars believe that technological innovation of digital technology is conducive for enterprises to develop dynamic capabilities to respond to supply chain risks well. Digitization is based on the integration of information technology to im- 
prove the enterprise's data processing ability as well as digital information-sharing ability; thus, it can provide an electronic connection between enterprises across organizational boundaries, and significantly promote the efficiency of the supply chain $[29,30]$; moreover, the digitization makes an intelligent supply chain operation possible.

Various research has proven that advanced digital technologies will produce a positive effect on supply chain's flexibility. For example, technological innovation could improve the management precision and thus improve the flexibility of the supply chain [31]; technological flexibility will stimulate enterprises' transformation and renewal, and thus has a positive impact on the supply chain flexibility [32]. Facing the impact of the COVID-19 pandemic, digitization can promote the emergence of new supply chain operation models, such as intelligent production, and intelligent logistics, etc. Digitization helps enterprises to strengthen their information processing capabilities so as to quickly respond to the market. All in all, in today's increasingly uncertain business environment, the digitization of enterprises makes it possible to share information instantly, gather participants' abilities together to stabilize the operation, improve the efficiency, and enhance the supply chain flexibility.

Therefore, this article puts forward the first hypothesis:

Hypothesis 1 (H1). Digitization positively influences the flexibility of the supply chain.

\subsection{Digitization and Collaborative Knowledge Creation}

The concept of collaborative management of the supply chain refers to an innovation model of collaborative operation where upstream and downstream enterprises work in synergy to drive good performance and share the benefits and risks together with the aim of improving the overall economic, environmental, and social performance of the whole supply chain.

Collaborative knowledge creation, as a newly emerged cross-organizational operation model, requires the effective flow of information between supply chain organizations, so that the management knowledge, technical knowledge, and institutional knowledge contained in the system can be transferred freely and speedily [33]. Many enterprises have used information systems to help them create new business opportunities, analyzing sales trends and summarizing customer preferences. For example, Rosetta-Net, which is widely used in the electronics industry, and DMS system, which is used in the automotive industry, are digital software applied in the intelligent supply chain by which the whole process of the production end-to-consumption end can be seen and traced throughout.

In a word, digital technologies can support the information flow smoothly among the supply chain and carry out a series of intelligent processes. Therefore, it can be seen that digitization plays a very important role in technically supporting, facilitating, and accelerating the collaborative knowledge creation.

Therefore, this article puts forward the second hypothesis:

\section{Hypothesis 2 (H2). Digitization positively influences collaborative knowledge creation.}

\subsection{Collaborative Knowledge Creation and Supply Chain Flexibility}

In today's market competition, where uncertainty increases intensively, cross-functional and cross-organizational supply chain collaboration will enhance supply chain flexibility and thus enhance supply chain competitiveness [26]. Manthou et al. and Stank et al. [34,35] believe that supply chain collaboration is a joint effort made by multiple enterprise members in the supply chain to realize resource sharing through internal and external business connection. In fact, the concept of collaborative knowledge creation is generated by integrating the concepts of 'synergy' and 'knowledge innovation'; it advocates building the collaborative ability between organizations on the basis of knowledge sharing and knowledge creation. In other words, it hopes to bring economic benefits to each enterprise through the creation of new knowledge, and improve the overall competitive advantage of the supply chain [36]. Effective knowledge transfer, management, and innovation among 
organizations can improve enterprises' customer responsiveness, enabling enterprises to better solve various uncertain problems in the process of production and operation [17]. Therefore, collaborative innovation is the key to building a sustainable supply chain, improving the supply chain's economic, environmental, and social performance [37].

In a word, through joint and collaborative operation of the supply chain, member enterprises can create new knowledge and practices of manufacturing, inventory, marketing, etc., so as to effectively cope with big changes and uncertainties.

Therefore, this article proposes the following hypotheses:

Hypothesis 3 (H3). Collaborative knowledge creation positively influences the supply chain flexibility;

Hypothesis 4 (H4). Collaborative knowledge creation plays a mediating role in the relationship between digitization and supply chain flexibility.

\subsection{Supply Chain Flexibility and Supply Chain Sustainability}

A supply chain is sustainable when the economic, environmental, and social benefits of all stakeholders are considered over a long period [38]. Marchese et al. believe that flexible ability can enhance sustainability in turbulent environments [39]. In the supply chain management, improving the supply chain flexibility is conducive to improving the anti-risk ability of the supply chain and thus promote the continuous operation of the supply chain. Samudi et al. used the structural equation model to explore how agility and flexibility affects the Australian manufacturing supply chain's economic, social, and environment sustainability. The results show that the flexibility of the supply chain has a great positive influence on the supply chain's social and environmental sustainability. Ruiz-Benitez R. et al. have applied lean and elastic practices to supply chains to evaluate their influences on the three dimensions of sustainability performance; all influence results were found to be positive [40].

Therefore, this article attempts to put forward the following hypotheses:

Hypothesis 5a (H5a). Supply chain digitization will positively affect the sustainability performance of the supply chain;

Hypothesis $\mathbf{5 b} \mathbf{( H 5 b ) . ~ C o l l a b o r a t i v e ~ k n o w l e d g e ~ c r e a t i o n ~ p o s i t i v e l y ~ i n f l u e n c e s ~ t h e ~ s u s t a i n a b i l i t y ~}$ performance of the supply chain.

Hypothesis 5c (H5c). Supply chain flexibility positively influences the sustainability performance of the supply chain;

Hypothesis 6 (H6). Supply chain flexibility plays a mediating role in the relationship between collaborative knowledge creation and supply chain sustainability performance;

Hypothesis 7 (H7). Collaborative knowledge creation and supply chain flexibility jointly play multiple mediating roles in the relationship between digitization and supply chain sustainability performance.

\subsection{The Moderating Effect of Market Uncertainty}

Market uncertainty refers to unexpected or unpredictable changes in the market [41]. When the environment is highly dynamic, in order to adapt to the rapidly changing market demands, enterprises must quickly acquire new resources and build new capabilities to realize organizational innovation [42]. Many scholars believe that, in an uncertain environment, organizational flexibility can improve organization performance $[43,44]$. Therefore, in the face of high market uncertainty, supply chain flexibility can provide companies with a better operation mode, so as to improve the sustainability performance of the supply chain. What is more, the higher the degree of market uncertainty, the better the supply chain flexibility can promote the performance of the supply chain and maintain its 
sustainability; the lower the degree of market uncertainty, the lower the positive promoting effect of supply chain flexibility on the sustainable ability of the supply chain.

Therefore, this article proposes the following hypothesis:

Hypothesis 8 (H8). Market uncertainty produces a positive moderating effect in the path of supply chain flexibility towards the supply chain's sustainability performance.

Integrating the above relationships and all the Hypotheses $\mathrm{H} 1-\mathrm{H} 8$, this study supposes that collaborative knowledge creation and supply chain flexibility are likely to play multiple mediating roles in the influence mechanism of digitization on supply chain sustainability performance. Moreover, market uncertainty is likely to have a moderating effect on the path between supply chain flexibility and supply chain sustainability performance. Therefore, this article proposes the following conceptual model, as shown in Figure 4.

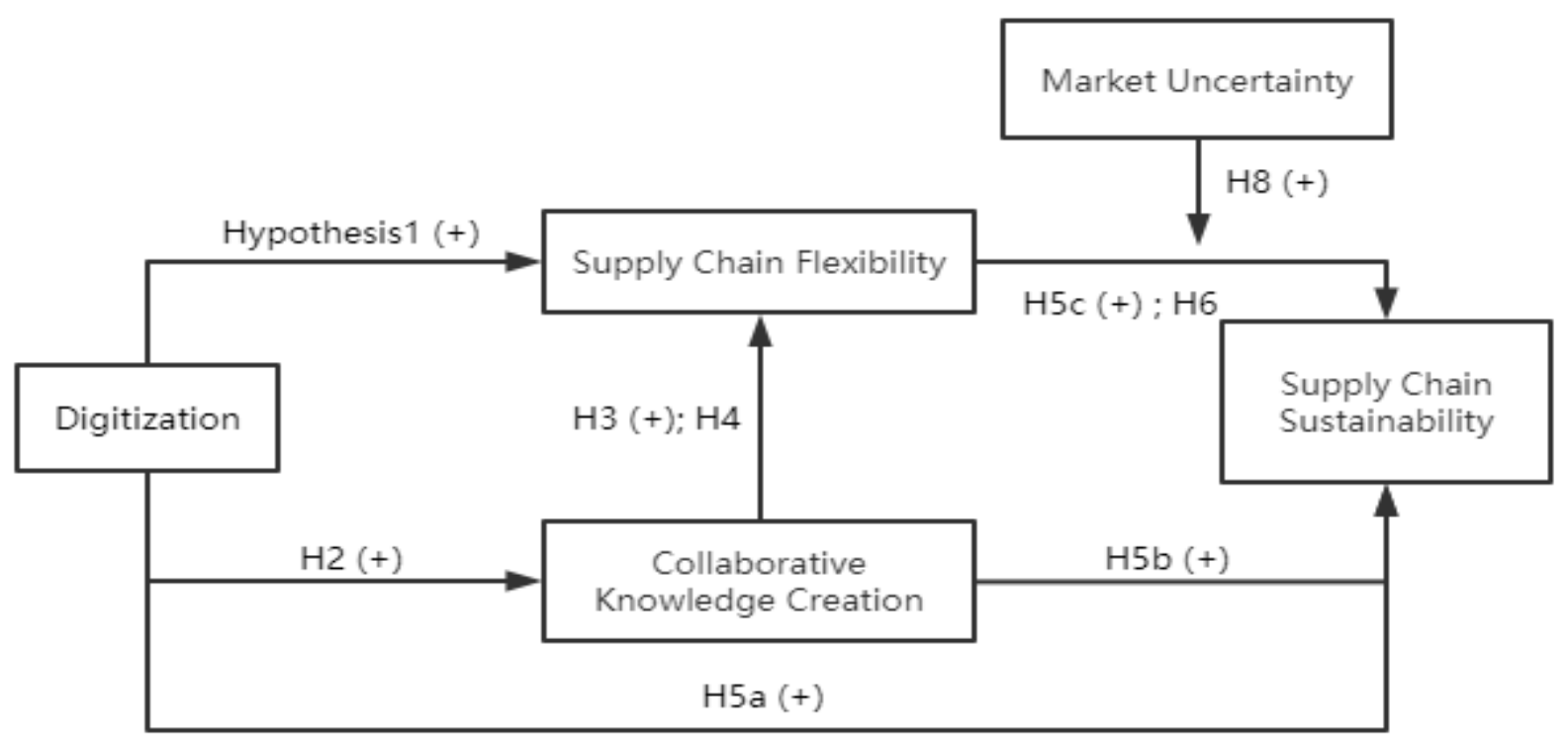

Figure 4. Conceptual Model.

\section{Research Methods}

\subsection{Research Sample}

Before the formal investigation, questionnaires were sent to 20 scholars and professors of the related research field for review. For the ambiguities in the question items that are easy misunderstand, such as "self-generation" and "self-replenishment," these expressions are modified into descriptive and explanatory sentences. "Self-generation" was explained into "SCF6" and "Self-replenishment" into "SCF7." For the question items that cannot measure the concept well, they were deleted.

In order to avoid sample selection bias and improve the universality and randomness of the samples, this study takes employees in various industries such as construction, manufacturing, IT, logistics, retail industry, and others. In addition, we chose employees working in purchasing/logistics/manufacturing departments as a research sample since they possess enough professional knowledge of the supply chain management, which would help them to correctly understand the question items. Finally, we asked supervisors of purchasing/logistics/manufacturing departments to send questionnaires to all the employees in their departments, excluding the individual heterogeneity factor that can affect employee's choice of participation. Samples of the study were collected from different industries in different provinces in China. Each question was required to be answered, so that there was no missing value in the submitted questionnaire. A total of 323 valid samples were finally obtained and the descriptive statistical analysis of the samples was shown in Table 2. 
Table 2. Descriptive Statistical Analysis of the Study Samples.

\begin{tabular}{cccc}
\hline Survey Item & Classification & Number & Ratio (\%) \\
\hline \multirow{4}{*}{ Enterprise Nature } & State-owned/State-owned holding & 96 & 30 \\
& Private-owned & 83 & 25.7 \\
& Sino-foreign joint venture & 72 & 22.5 \\
& Foreign-owned & 72 & 22.5 \\
\hline \multirow{3}{*}{ Industry Involved } & Construction & 80 & 25 \\
& IT/Hardware-software & 63 & 19.5 \\
& service/E-business/Internet Operation & 92 & 28.75 \\
& Manufacturing & 88 & 27.5 \\
\hline \multirow{2}{*}{ Staff Size } & Transportation/Logistics & 151 & 46.75 \\
& <500 & 52 & 16.25 \\
& 500-1000 & 12 & 3.75 \\
& 1001-2000 & 108 & 33.75 \\
\hline \multirow{3}{*}{ Staff Position } & $>$ 2000 & 24 & 7.5 \\
& Senior Manager & 52 & 16.25 \\
& Middle-level Manager & 112 & 35 \\
& First-line Manager & 135 & 41.8 \\
\hline
\end{tabular}

Then, the article verifies the reliability and validity of the questionnaires and uses the structural model equation to test the model's correctness. In order to be sure of the conceptual model's robustness, the Bootstrapping method was used to verify each mediation effect path as well as the moderation effect. To better observe digitization, collaborative knowledge creation, and supply chain flexibility's respective and joint influence on supply chain's sustainability, the hierarchical regression is adopted at last with company staff size, company nature, and industry involved controlled.

\subsection{Survey Instruments}

The questionnaire is divided into six parts with the first part being the basic information of the enterprise, which can be considered as control variables; the other five sub-scales are displayed as follows. A Likert 5-point scale was adopted for all scales in this study, in which ' 1 ' means strongly disagree and ' 5 ' means strongly agree.

Supply chain flexibility: this sub-scale mainly refers to the research of Vickery et al. [45], Sreedevi and Saranga [18], and Eckstein et al. [19]. There are seven items in this sub-scale, such as 'Is your enterprise able to cope with fundamental changes in the market?' 'Do you think the enterprise is trying to adapt to the risk and execute risk management in decisionmaking?' 'Do you think the enterprise has the ability to cope with the technological fundamental changes and keep up with the technological progress?' etc.

Digitization of supply chain: the multidimensional scale developed and compiled by Wang R. et al. [46] is selected as a reference. This sub-scale contains three questions, such as: 'Whether the enterprise has accelerated the construction of digital infrastructure?' 'Has your enterprise already run the joint digital supply chain platform among the customers, distributors and suppliers?' etc.

Knowledge collaborative creation: this sub-scale uses Eseryel's [36] scale of three projects, such as 'Does your enterprise solve the problem of the supply chain through collaborative methods?' 'Has the enterprise built the knowledge development team and the knowledge sharing platform?' etc.

Market uncertainty scale basically refers to the scale of Vickery et al. [45], which is made up of four measurement items, such as 'The market's product demand changes very quickly.' 'The quantity and quality of suppliers' resource are unstable,' etc.

Supply chain sustainability scale: sustainability depends on three fundamental pillars: economic, environmental, and social, formally known as profit, planet, and people. Quite a few studies support this perspective. Seok et al. [38] believe that the three essential 
pillars of a sustainable supply chain are economic, environmental, and social. Similarly, Elkington's 'Triple-bottom line' principle also believes in the process of pursuing supply chain development, enterprises should simultaneously meet the overall goals of economic prosperity, environmental protection, and social well-being, keeping them developed at the same time [47]. Given environmental benefits, reduction in carbon emission is one of the main objectives for any sustainable supply chain system [48-50]. Because of social responsibilities, different firms upgrade the relationship between social sustainability and financial performance [51]. Therefore, this study will refer to the scale developed by Lee J et al. [52], measuring supply chain sustainability from economic, social, and environmental dimensions with a total of three items, such as 'My enterprise provides technology, management, and financial assistance to solve social problems' and 'We have implemented a quality and environmental management system such as ISO18000/14000,' etc.

\subsection{Analysis Technique}

In this study, SPSS 22.0 software was used for descriptive statistical analysis and correlation analysis, and AMOS18.0 software was used for confirmatory factor analysis and structural equation model analysis. SPSS macro program ProcessV3.3 was used to test the direct effect, multiple mediation effect, and moderation effect of the built model through the Bootstrap method, which is recommended by the academic community [53-55].

\section{Research Results}

\subsection{Common Method Variance Test and Model Goodness of Fit}

Since the sample data were collected by the same questionnaire, it is necessary to test the common method variance. The study used SPSS 22.0 to do the Harman single factor inspection to test whether the data have the problem of common method variance [56], and the results of principal component analysis showed that there were five common factors whose eigenvalue is greater than 1 , and the cumulative variance of these five factors was $76.4 \%$, with the first main component's factor variance contribution lower than $40 \%$. More than one common factor can be extracted from all the questionnaire items; the data used in this study have no serious common method bias problem.

In this study, confirmatory factor analysis was performed on latent variables to test the model goodness of fit of the conceptual model. The fitting indexes of the five-factor/ four-factor/three-factor models are shown in Table 3, results indicating that the five-factor established model is the most acceptable.

Table 3. Confirmatory Factor Analysis Results.

\begin{tabular}{cccccccc}
\hline Model Type & $\chi^{\mathbf{2}}$ & $d f$ & RMSEA & CFI & IFI & NFI & NNFI \\
\hline M1:DC, CKC, SCF, SP, MU & 292.7 & 85 & 0.087 & 0.95 & 0.95 & 0.93 & 0.93 \\
M2: DC + CKC, SCF, SP, MU & 814.57 & 92 & 0.157 & 0.84 & 0.84 & 0.82 & 0.79 \\
M3: DC, CKC + SCF, SP, MU & 769.30 & 91 & 0.153 & 0.85 & 0.85 & 0.83 & 0.80 \\
M4: DC, CKC, SCF + SP, MU & 854.60 & 90 & 0.163 & 0.82 & 0.83 & 0.81 & 0.77 \\
M5: DC + CKC + SCF, SP, MU & 896.70 & 93 & 0.165 & 0.82 & 0.82 & 0.80 & 0.77 \\
\hline
\end{tabular}

Note: $\mathrm{N}=323, \mathrm{DC}=$ Digitization capability, SCF = Supply chain flexibility, CKC = Collaborative knowledge creation, $\mathrm{SP}=$ Sustainability Performance, $\mathrm{MU}=$ Market Uncertainty.

\subsection{Convergent and Discriminant Validity Verification}

The VIF of all variables were below the recommended threshold of 10, indicating that there was no serious multi-collinearity problem. The overall Cronbach's $\alpha$ of the questionnaire in this study was 0.92 , and the reliability analysis results of all latent variables involved were shown in Table 4 . The Cronbach's $\alpha$ of the latent variables were all greater than 0.7 , indicating that the reliability of the scale was good. It can be seen from Table 3 that the standard loading of all items is greater than $0.6, \mathrm{CR}$ value is greater than 0.7, and AVE is greater than 0.5 . The convergence validity of the model is acceptable. Discriminant validity can be investigated by comparing the square of the correlation coefficient between the 
two latent variables with the value of AVE [57]. In Table 4, the values on the diagonal are AVE values of each latent variable, comparing AVE values with the correlation coefficients among variables; the correlation coefficients among all latent variables are not higher than the respective square root of AVE, indicating that the latent variables have good discriminant validity.

Table 4. Reliability and Validity Test of all Variables $(\mathrm{N}=323)$.

\begin{tabular}{|c|c|c|c|c|c|}
\hline Variable & Item & Loading & Cronbach's $\alpha$ & CR & AVE \\
\hline Digital Capability & $\begin{array}{c}\text { DC1 Enterprises build digital supply chain } \\
\text { development strategy } \\
\text { DC2 Enterprises accelerate the construction of } \\
\text { digital infrastructure } \\
\text { DC3 Enterprises have run digital supply chain platforms } \\
\text { with customers, distributors and suppliers }\end{array}$ & $\begin{array}{c}0.779 \\
0.825 \\
0.64\end{array}$ & 0.77 & 0.79 & 0.57 \\
\hline $\begin{array}{c}\text { Collaborative } \\
\text { Knowledge } \\
\text { Creation }\end{array}$ & $\begin{array}{c}\text { CKC1 Enterprises have been using a collaborative network } \\
\text { platform to solve supply chain problems } \\
\text { CKC2 Enterprises have knowledge creation team or } \\
\text { knowledge sharing platform } \\
\text { CKC3 Supply chain member enterprises have formed a } \\
\text { long-term healthy partnership }\end{array}$ & $\begin{array}{l}0.753 \\
0.694 \\
0.631\end{array}$ & 0.84 & 0.74 & 0.50 \\
\hline $\begin{array}{l}\text { Supply Chain } \\
\text { Flexibility }\end{array}$ & $\begin{array}{l}\text { SCF1 Enterprises can monitor and alert supply chain } \\
\text { operation risks by information data platform system } \\
\text { SCF2 The early warning system of supply chain is } \\
\text { established, which can predict the short-term technology } \\
\text { trend, price trend and supply \& demand change } \\
\text { SCF3 Enterprises can adjust supply chain structure to } \\
\text { respond to customer demand changes or a new supply } \\
\text { market pattern } \\
\text { SCF4 Enterprises can adjust production \& manufacturing } \\
\text { processes to respond to the fundamental technological } \\
\text { progress in the market } \\
\text { SCF5 Enterprises can adjust their daily production process, } \\
\text { output \& inventory level and distribution channel quickly } \\
\text { SCF6 The member enterprises of supply chain can generate } \\
\text { valuable and creative knowledge through } \\
\text { information interchange }\end{array}$ & $\begin{array}{c}0.81 \\
0.884 \\
0.857 \\
0.724\end{array}$ & 0.94 & 0.89 & 0.55 \\
\hline $\begin{array}{l}\text { Sustainability } \\
\text { Performance }\end{array}$ & $\begin{array}{l}\text { SD1 The enterprise has implemented environmental } \\
\text { management and evaluation system(ISO 180000/14000) } \\
\text { SD2 Enterprises provide environmentally friendly products } \\
\text { and services } \\
\text { SD3 Enterprises provide technical, managerial or financial } \\
\text { assistance to solve social problems }\end{array}$ & $\begin{array}{l}0.735 \\
0.693\end{array}$ & 0.83 & 0.79 & 0.55 \\
\hline $\begin{array}{c}\text { Market } \\
\text { Uncertainty }\end{array}$ & $\begin{array}{l}\text { MU1 Market production capacity and product capacity } \\
\text { are uncertain } \\
\text { MU2 Market demand and consumer preference for product } \\
\text { are uncertain } \\
\text { MU3 The competitive strategies of competitors are } \\
\text { uncertain } \\
\text { MU4 The quantity and quality of resources from suppliers } \\
\text { are not stable }\end{array}$ & $\begin{array}{l}0.794 \\
0.764 \\
0.635 \\
0.838\end{array}$ & 0.88 & 0.85 & 0.58 \\
\hline
\end{tabular}

\subsection{Correlation Analysis of Variables}

The correlation analysis of independent variables, mediation variables, and dependent variables in the model was conducted, finding that all of the correlation coefficients among 
the variables were significant. The descriptive statistical analysis result of variables was also shown in Table 5.

Table 5. Variable Mean, Standard Deviation, Correlation Coefficients $(\mathrm{N}=323)$.

\begin{tabular}{cccccc}
\hline & $\boldsymbol{M} \pm \boldsymbol{S D}$ & $\mathbf{1}$ & $\mathbf{2}$ & $\mathbf{3}$ & $\mathbf{4}$ \\
\hline 1. Digitization & $4.3 \pm 0.74$ & $(0.57)$ & & & \\
2. Collaborative Knowledge Creation & $4.08 \pm 0.83$ & $0.63^{* * *}$ & $(0.5)$ & & \\
3. Supply Chain Flexibility & $4.12 \pm 0.91$ & $0.68^{* * *}$ & $0.69^{* * *}$ & $(0.55)$ & \\
4. Supply Chain Sustainability & $4.15 \pm 0.79$ & $0.58^{* * *}$ & $0.7^{* * *}$ & $0.7^{* * *}$ & $(0.55)$ \\
\hline Note: $\mathrm{M}=$ mean, SD = standard deviation, ( ) in the table means AVE of latent variables, ${ }^{* * *}$ means $p<0.001$.
\end{tabular}

According to the correlation coefficient of each variable, there was a significant positive correlation between digital capability and collaborative knowledge creation $(\mathrm{r}=0.63$, $p<0.001$ ); there was a significant positive correlation between digital capability and supply chain flexibility $(r=0.68, p<0.001)$, and correlation between the digital capability and sustainable development of the supply chain was also significantly positive $(r=0.58$, $p<0.001$ ). Collaborative knowledge creation and supply chain flexibility were positively correlated, the same as the collaborative knowledge creation and supply chain sustainability $(r=0.69, p<0.001 ; R=0.71, p<0.001)$. Finally, there was a significant positive correlation between supply chain flexibility and its sustainable development $(\mathrm{r}=0.7, p<0.001)$. It can be seen that all the variables are significantly correlated, which provides preliminary support for the verification of the theoretical model.

\subsection{Structural Equation Model Results}

In order to determine the path relationship among latent variables involved in this study, as well as to verify the multiple mediating effects and moderating effects, AMOS18.0 software was used to test the structural equation model, and the significance of each path was analyzed through the $t$-test results. The standardized coefficients between paths of the structural equation model were shown in Figure 5.

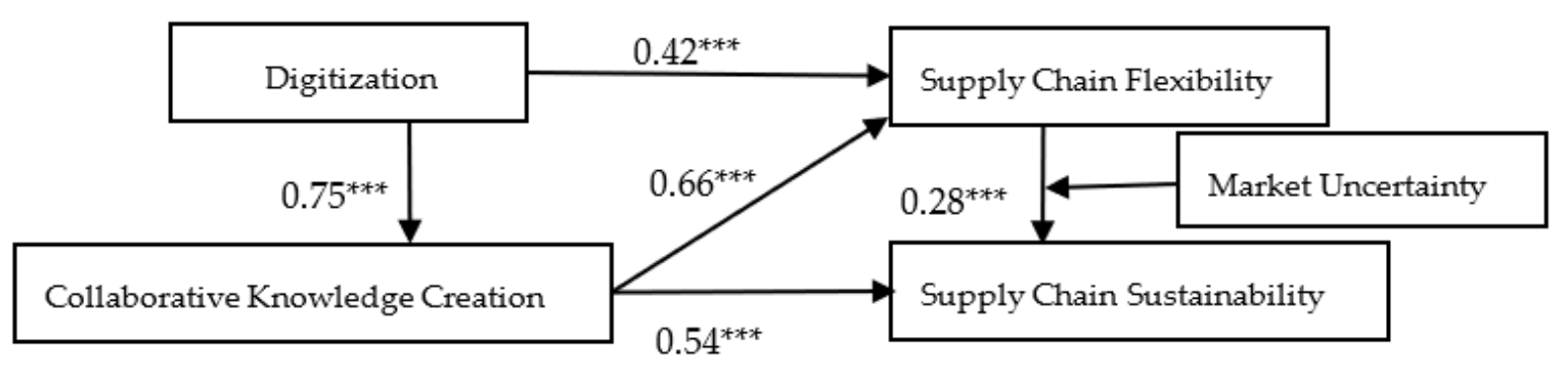

Figure 5. Path Coefficients of SEM. Note: $\mathrm{N}=323,{ }^{* *}$ means $p<0.01,{ }^{* * *}$ means $p<0.001$.

The structural equation model test shows that digitization has a significant positive impact on supply chain flexibility $(\beta=0.42, p<0.001)$ and, thus, $\mathrm{H} 1$ is verified. At the same time, digital ability also has a significant positive impact on collaborative knowledge creation $(\beta=0.75, p<0.001)$ and, thus, $\mathrm{H} 2$ is verified.

Collaborative knowledge creation significantly positively affects the supply chain flexibility $(\beta=0.66, p<0.001)$ and, hence, $\mathrm{H} 3$ is verified.

In addition to the direct influence of digitization on supply chain flexibility, digitization also affects supply chain flexibility through collaborative knowledge creation, and its path coefficient is also significant $(\beta=0.75, p<0.001 ; \beta=0.66, p<0.001)$. That is, collaborative knowledge creation plays a mediating role between digitization and supply chain flexibility and, thus, $\mathrm{H} 4$ is verified.

Collaborative knowledge creation significantly positively affects the supply chain sustainability $(\beta=0.54, p<0.001)$. The supply chain flexibility also significantly positively affects the supply chain sustainability $(\beta=0.28, p<0.01, p=0.006)$. Hence, $\mathrm{H} 5$ is verified. 
In addition to the direct positive impact of collaborative knowledge creation on the supply chain sustainability, it also affects supply chain sustainability through supply chain flexibility, and the coefficient of this influence path is significant $(\beta=0.66, p<0.001$; $\beta=0.28, p<0.01)$. That is, supply chain flexibility plays a mediating role between collaborative knowledge creation and supply chain sustainability. Thus, H6 is verified.

In conclusion, digitization influences supply chain sustainability significantly through collaborative knowledge creation and supply chain flexibility, with the coefficient of this multiple mediation path being $0.75 \times 0.66 \times 0.28=0.14$. Therefore, $\mathrm{H} 7$ is verified. In addition, the path coefficient of 'digitization $\rightarrow$ collaborative knowledge creation $\rightarrow$ supply chain sustainability' is $0.75 \times 0.54=0.4$. The coefficient of path 'digitization $\rightarrow$ supply chain flexibility $\rightarrow$ supply chain sustainability' is $0.42 \times 0.28=0.12$. According to the $t$-test results, all three of these mediation path coefficients are highly significant.

\subsection{Bootstrap Method Verification}

In this article, the significance of each mediation path, as well as the moderating effect, was tested by the deviation-corrected percentile Bootstrap program, with repeated extraction done 5000 times. The $95 \%$ confidence interval was obtained. Variables of market uncertainty and supply chain flexibility have been mean-centered, and the direct and indirect mediating effects can be seen from Table 6.

Table 6. Bootstrap Verification Results of Mediation Impact Pathways.

\begin{tabular}{|c|c|c|c|c|}
\hline Impact Paths & Estimate & Boot SE & $\begin{array}{l}\text { Bootstrap } \\
(95 \% \mathrm{CI})\end{array}$ & $\begin{array}{c}\text { Relative Mediation } \\
\text { Effect }\end{array}$ \\
\hline Mediation Impact $1: \mathrm{DC} \rightarrow \mathrm{CKC} \rightarrow \mathrm{SP}$ & 0.153 & 0.029 & {$[0.1,0.215]$} & $41.3 \%$ \\
\hline Mediation Impact $2: \mathrm{DC} \rightarrow \mathrm{SCF} \rightarrow \mathrm{SP}$ & 0.038 & 0.016 & {$[0.01,0.074]$} & $10.3 \%$ \\
\hline Mediation Impact 3: $\mathrm{DC} \rightarrow \mathrm{CKC} \rightarrow \mathrm{SCF} \rightarrow \mathrm{SP}$ & 0.043 & 0.016 & {$[0.012,0.076]$} & $11.6 \%$ \\
\hline Moderating Impact SCF $\times \mathrm{MU} \rightarrow \mathrm{SP}$ & 0.037 & 0.011 & {$[0.016,0.059]$} & \\
\hline Total Mediation Effect & 0.234 & 0.031 & {$[0.178,0.297]$} & $63.2 \%$ \\
\hline Total Effect & 0.37 & 0.03 & {$[0.311,0.428]$} & $100 \%$ \\
\hline Comparison of Mediation impact 2 to 1 & 0.115 & 0.039 & {$[0.04,0.193]$} & \\
\hline Comparison of Mediation impact 1 to 3 & 0.11 & 0.039 & {$[0.039,0.191]$} & \\
\hline Comparison of Mediation impact 2 to 3 & -0.004 & 0.013 & {$[-0.032,0.022]$} & \\
\hline
\end{tabular}

Note: $\mathrm{N}=323, \mathrm{DC}=$ Digitization capability, $\mathrm{SCF}=$ Supply chain flexibility, $\mathrm{CKC}=$ Collaborative knowledge creation, $\mathrm{SP}=\mathrm{Sustainability}$ Performance, $\mathrm{MU}=$ Market Uncertainty.

Mediation paths in the model include 'Digitization $\rightarrow$ collaborative knowledge creation $\rightarrow$ supply chain flexibility $\rightarrow$ supply chain sustainability' whose Bootstrap confidence intervals $(95 \% \mathrm{CI})$ are $[0.012,0.076]$. The path 'digitization $\rightarrow$ collaborative knowledge creation $\rightarrow$ supply chain sustainability' has a confidence interval of [0.1, 0.215$]$. The path 'digitization $\rightarrow$ supply chain flexibility $\rightarrow$ supply chain sustainability' has a confidence interval $(95 \%$ CI) for $[0.01,0.074]$. All three of these confidence intervals contain no 0 , showing that the multiple mediating effects of the three pathways were all significant. The Bootstrap $(95 \% \mathrm{CI})$ confidence interval of the path 'supply chain flexibility $\times$ market uncertainty $\rightarrow$ supply chain sustainability' is [0.016, 0.059], also includes no 0 . This is a preliminary finding indicating that market uncertainty plays a moderating role in the influence mechanism between supply chain flexibility and supply chain sustainability performance.

Through structural equation modeling, we can find that: firstly, the impact of digitization on supply chain sustainability is mediated jointly by collaborative knowledge creation and supply chain flexibility; secondly, the impact of digitization on supply chain sustainability can be mediated only by collaborative knowledge creation; thirdly, the impact of digitization on supply chain sustainability can be mediated only by supply chain flexibility. There are multiple mediation pathways. As a moderating variable, the interaction item between market uncertainty and supply chain flexibility has a significant positive impact on the supply chain sustainability. Hypothesis $\mathrm{H} 8$ can be preliminarily verified. 
It can also be seen from Table 6 that the estimated total effect of digitization on the sustainability performance of the supply chain is 0.37 . The estimated $95 \%$ confidence interval of Bootstrap is $[0.311,0.428]$. The estimated total mediating effect is 0.234 with the confidence interval $[0.178,0.297]$. We can see that both the total effect and the total mediating effect are significant. In addition, the influence power of different mediating paths is also compared. The confidence interval of 'comparison between mediation impact 1 and $2^{\prime}$ is [0.04, 0.193], and that of the 'comparison between 1 and $3^{\prime}$ is [0.039, 0.191], all excluding 0 , indicating that the power of the 'mediation impact $2^{\prime}$ is significantly higher than the power of 'impact 1 and $3^{\prime}$. However, the confidence interval of the 'comparison between the mediation impact 2 and $3^{\prime}$ is $[-0.032,0.022]$, including 0 , which means that there was little difference in the influence of the force between the mediating effects 2 and 3. Therefore, the mediation effect of the 'supply chain digitization $\rightarrow$ collaborative knowledge creation $\rightarrow$ sustainability performance' path is the strongest among three significant mediation paths.

\subsection{Further Exploration of the Moderating Effect}

In order to test the moderating effect of market uncertainty, the involved variables were centralized, and the interaction item was standardized before analysis. The results of Bootstrap analysis shown in Table 6 indicate that market uncertainty has a significant positive moderating effect on supply chain flexibility's influence on supply chain sustainability performance $(\beta=0.037, p<0.001 ; 95 \% C I=[0.016,0.059]$, excluding the zero point).

To further explore the moderating effects under different degrees of market uncertainty, an interactive plot analysis was carried out based on one standard deviation above and below the mean value of the market uncertainty, with the results shown in Figure 6. As can be seen from Figure 3, the greater the market uncertainty is, the stronger the positive effect of supply chain flexibility on the sustainability performance of the supply chain is. On the contrary, the smaller the market uncertainty is, the weaker the positive effect of supply chain flexibility on the sustainability performance of the supply chain is.

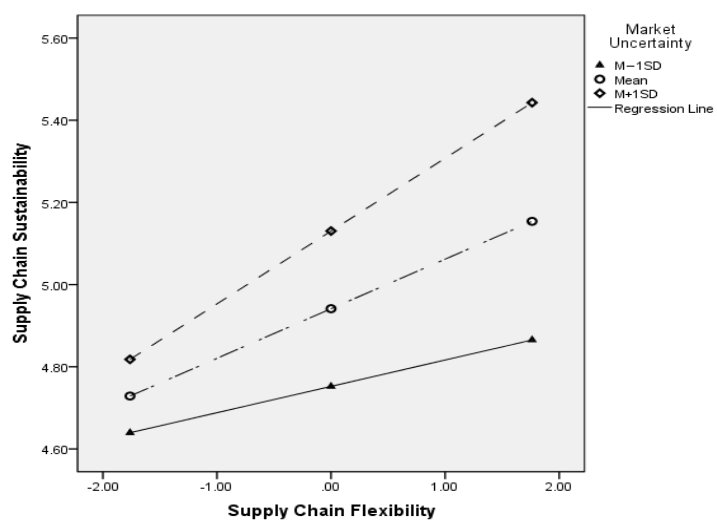

(a)

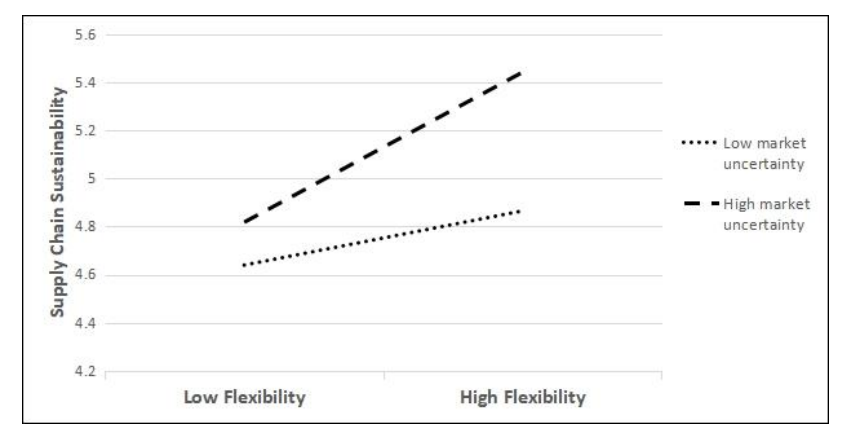

(b)

Figure 6. Slope Figure of Market Uncertainty Moderating Effect (a). Slope Figure of Market Uncertainty Moderating Effect (b).

In order to ensure the robustness of the moderating effect of market uncertainty, the Bootstrap method of SPSS Process Model 14 was adopted in this study to conduct the verification analysis. Before the analysis, the involved variables were centralized, and the interaction items were standardized. The grading results are shown in Table 6: on the basis of market uncertainty's mean value and mean value $+1 S D$, the confidence interval at the 95\% level of the mediation path 'collaborative knowledge creation $\rightarrow$ supply chain flexibility $\rightarrow$ supply chain sustainability performance' does not contain 0 , indicating that under the condition of high environmental uncertainty, the market uncertainty will have a significant moderating effect on the mediating path of supply chain 
flexibility $\rightarrow$ supply chain sustainability performance. However, on the basis of market uncertainty's mean value $-1 \mathrm{SD}$, or under the condition of low market uncertainty, the mediating effect of supply chain flexibility on the supply chain's sustainability performance will not be significantly moderated by market uncertainty. Therefore, the greater the market uncertainty is, the more positive the effects that supply chain flexibility will bring to the sustainability performance of the supply chain. Overall, Table 7 shows that the moderated mediating effect index is $\beta=0.004,95 \% \mathrm{CI}=[0.002,0.079]$, excluding the zero point, which indicates that market uncertainty does have a significant positive moderating effect on the mediating path 'collaborative knowledge creation $\rightarrow$ supply chain flexibility $\rightarrow$ supply chain sustainability performance' as a whole. Hypothesis H8 is verified. This research model has a moderated mediating effect.

Table 7. Bootstrap Verification Results of Moderated Mediation Pathway.

\begin{tabular}{|c|c|c|c|c|c|c|c|}
\hline \multirow{2}{*}{$\begin{array}{c}\text { Indirect Impact } \\
\text { Path }\end{array}$} & \multirow{2}{*}{$\begin{array}{l}\text { Moderator: } \\
\text { MU }\end{array}$} & \multicolumn{3}{|c|}{ Mediation Effect } & \multicolumn{3}{|c|}{ Moderated Mediation Effect } \\
\hline & & Estimates & Boot SE & $\begin{array}{c}\text { Bootstrap } \\
(95 \% \mathrm{CI})\end{array}$ & Estimates & Boot SE & $\begin{array}{c}\text { Bootstrap } \\
(95 \% \mathrm{CI})\end{array}$ \\
\hline \multirow[t]{3}{*}{$\mathrm{CKC} \rightarrow \mathrm{SCF} \rightarrow \mathrm{SP}$} & Mean - 1SD & 0.076 & 0.045 & {$[-0.006,0.171]$} & 0.044 & 0.021 & {$[0.002,0.079]$} \\
\hline & Mean & 0.144 & 0.037 & {$[0.072,0.216]$} & & & \\
\hline & Mean + 1SD & 0.212 & 0.051 & {$[0.106,0.307]$} & & & \\
\hline
\end{tabular}

Note: $\mathrm{N}=323, \mathrm{DC}=$ Digitization capability, $\mathrm{SCF}=$ Supply chain flexibility, CKC = Collaborative knowledge creation, $\mathrm{SP}=$ Sustainability Performance, $\mathrm{MU}=$ Market Uncertainty.

\subsection{Hierarchical Regression}

To improve the samples' universality, research samples were chosen from different industries and different companies; however, to exclude different industries or companies' individual heterogeneous influence on supply chain's sustainability performance, some factors such as company nature, size, and industry involved should be controlled.

According to the results in Table 8, (1) digitization has a significant positive impact on supply chain flexibility (M4, $\beta=0.79, p \leq 0.01$ ), which supports Hypothesis 1 ; (2) digitization has a significant positive impact on knowledge collaborative creation (M2, $\beta=0.745, p \leq 0.01$ ), which supports Hypothesis 2; (3) Collaborative knowledge creation has a significant positive impact on supply chain flexibility (M5, $\beta=0.67, p \leq 0.01$ ), which supports Hypothesis 3; Moreover, with the addition of collaborative knowledge creation, the influence of digitization on supply chain flexibility is reduced to (M5, $\beta=0.29$, $p \leq 0.01$ ), indicating that collaborative knowledge creation plays a partially mediating role, supporting Hypothesis 4 ; (4) digitization (M7, $\beta=0.603, p \leq 0.01)$, collaborative knowledge creation (M8, $\beta=0.476, p \leq 0.01$ ), and supply chain flexibility (M9, $\beta=0.35$, $p \leq 0.01$ ) all have a significant positive impact on supply chain sustainability, which verifies Hypothesis 5a, 5b, and 5c. However, with the addition of collaborative knowledge creation, the influence coefficient of digitization is reduced to 0.25 , and with the addition of supply chain flexibility, the coefficient of digitization and collaborative knowledge creation is reduced to 0.149 and 0.242 , respectively. This indicates that collaborative knowledge creation and supply chain flexibility play multiple mediating roles, and hypothesis 6 is verified.

In order to test the moderating effect of market uncertainty, the supply chain sustainability is taken as the dependent variable, then control variable (company nature, company size, industry), independent variable (supply chain flexibility), and moderating variable (market uncertainty) are introduced successively, and, finally, the interaction of the independent variable and moderating variable is added. As can be seen from Table 8, the interaction between supply chain flexibility and market uncertainty has a significant positive impact on supply chain sustainability (M10, $\beta=0.065, p \leq 0.01$ ), which indicates that the higher the uncertainty of the environment is, the more conducive the supply chain flexibility is to the supply chain's sustainability. Therefore, Hypothesis 8 is supported by the data. 
Table 8. Hierarchical Regression Results of Moderated Mediation Pathways.

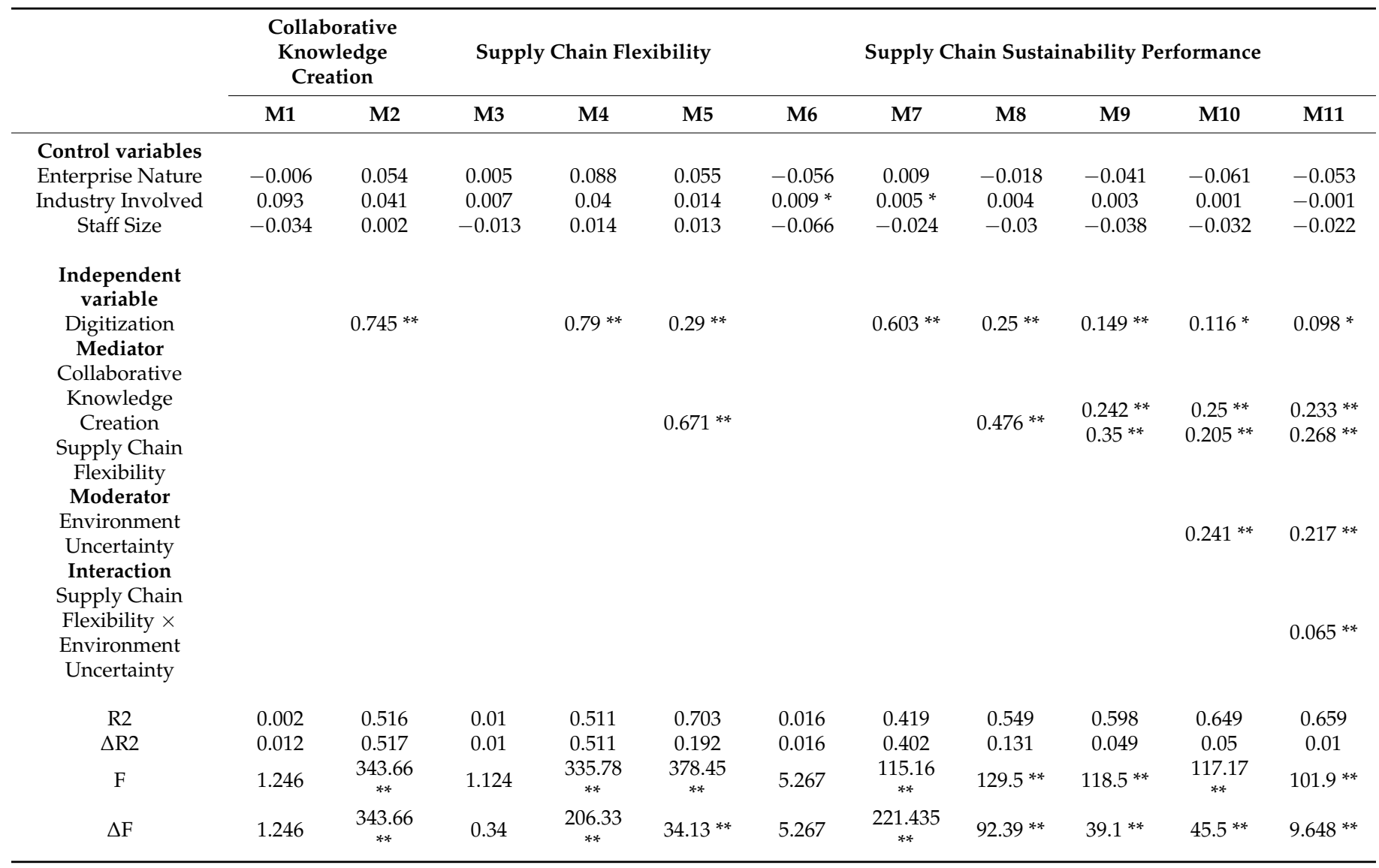

Notes: $\mathrm{N}=323 ;{ }^{*}$ means $p<0.05,{ }^{* *}$ means $p<0.01$ (two-tailed).

\section{Conclusions and Implication}

\subsection{Research Conclusion}

First, digitization has a significant positive effect on collaborative knowledge creation, supply chain flexibility, and the sustainability performance of the supply chain. This result is similar to that of Araz et al. (2020) [58] and Ivanov (2020) [59]; then, collaborative knowledge creation and supply chain flexibility all have significant positive effects on supply chain sustainability performance, respectively.

Second, collaborative knowledge creation and supply chain flexibility play multiple mediating roles in the influence between digitization and the supply chain sustainability. In addition to the direct impact of digitization on the sustainability performance of the supply chain, the partial mediating effect shown by multiple mediation paths should be respectively discussed. The first mediation path is 'digitization $\rightarrow$ collaborative knowledge creation $\rightarrow$ sustainability performance of the supply chain,' while the second path is 'digitization $\rightarrow$ supply chain flexibility $\rightarrow$ sustainability performance,' and the last path is 'supply chain digitization $\rightarrow$ collaborative knowledge creation $\rightarrow$ flexibility $\rightarrow$ supply chain sustainability.' This in-depth analysis of influencing mechanisms will help to obtain more targeted management advice.

Third, the impact of supply chain flexibility on supply chain sustainability is of different intensities when in the environments of high market uncertainty and low market uncertainty. The higher the market uncertainty is, the more positive the promoting effect that supply chain flexibility will bring to the sustainability performance of the supply chain. When the market environment is stable and simple, supply chain flexibility cannot display its influence on the supply chain's sustainability performance. Therefore, a supply chain with a higher degree of flexibility can better adapt to the rapid changes of an uncertain environment and minimize the 
bad impact of uncertainty, thus improving the sustainability of the supply chain. The results are consistent with Hosseini et al. [13]; Craighead et al. [60]; Ho et al. [61].

\subsection{Managerial Implication}

Based on the above conclusions, the following three inspirations are summarized for the management practice of enterprises.

From a flexibility perspective, in order to make the supply chain develop in a sustainable way, each member enterprise in the supply chain should have the awareness to identify the risks of the supply chain proactively by building the early-warning system; it also needs to build an open, self-generative, and developmental-intelligent network to find a better and more cost-efficient way to respond to short or long-term changes in the uncertain environment. Therefore self-improvement and self-generation through intelligent supply chain networks could become a crucial determinant of the supply chain's sustainable development.

From the digitization perspective, noticing the wide application and rapid development of big data, AI, and many other digitized technologies, the member enterprises need to gradually transform into a digitized operation mode such as intelligent manufacturing, purchasing, supplier management, marketing \& sales, customer service, etc., and make efforts to improving the construction of information systems. Sufficient information sharing and data analysis can make full use of valuable knowledge resources to help enterprises make much more precise and quick decision.

From collaboration perspective, the success of any individual member of the supply chain always depends on the success of the supply chain as a whole; therefore, each member enterprise of the supply chain should pay special attention to further strengthening the cooperative partnership. A reasonable allocation and integration of internal and external resources will significantly improve the operation performance and competitiveness of the whole supply chain $[62,63]$.

\section{Research Prospect}

First of all, since the data used in this study are cross-sectional, they do not study the dynamic influence of digitization and flexibility over time. Therefore, the data of future research can be collected in different periods to show how digital capability and flexibility affect the supply chain sustainability over time.

Secondly, the number of survey samples involved in this study is limited, and the number of industries is also limited. Perhaps due to the particularity of the subject group, the results of this study cannot represent the situation of all supply chain member enterprises. The results of this study need to be further verified in a larger sample.

Thirdly, as for the moderating variable involved in this study, whether the market uncertainty acts on other mediation effect pathways or not is not discussed yet. For the paths of digitization or collaborative knowledge creation on the sustainable development of the supply chain, more moderating mechanisms are worthy of future research and discussion.

Author Contributions: Conceptualization, Q.Z., S.W.; methodology, Q.Z., S.W.; software, Q.Z.; formal analysis, Q.Z., S.W.; investigation, Q.Z.; resources, S.W.; writing —original draft preparation, Q.Z.; writing—-review and editing, Q.Z., S.W.; visualization, Q.Z. All authors have read and agreed to the published version of the manuscript.

Funding: This research received no external funding.

Institutional Review Board Statement: Not applicable.

Informed Consent Statement: Informed consent was obtained from all subjects involved in the study.

Data Availability Statement: The data used to support the findings of this study are available from the corresponding author upon request.

Acknowledgments: All individuals included in this section have consented to the acknowledgement. We sincerely express our heartfelt thanks to the reviewers and editors for their efforts.

Conflicts of Interest: The authors declare no conflict of interest. 


\section{References}

1. Huo, B.; Gu, M.; Wang, Z.S. Supply chain flexibility concepts, dimensions and outcomes: An organisational capability perspective. Int. J. Prod. Res. 2018, 56, 5883-5903. [CrossRef]

2. Chesbrough, H. To recover faster from covid-19, open up: Managerial implications from an open innovation perspective. Ind. Mark. Manag. 2020, 88, 410-413. [CrossRef]

3. Choi, T.Y.; Rogers, D.; Vakil, B. Coronavirus is a Wake-up Call for Supply Chain Management. Harv. Bus. Rev. 2020, 27, 364-398.

4. Chowdhury, M.M.H.; Agarwal, R.; Quaddus, M.A. Dynamic capabilities for meeting stakeholders' sustainability requirements in supply chain. J. Clean. Prod. 2019, 215, 34-35. [CrossRef]

5. Chowdhury, M.M.H.; Quaddus, M.A. Supply chain sustainability practices and governance for mitigating sustainability risk and improving market performance: A dynamic capability perspective. J. Clean. Prod. 2021, 278, 123521. [CrossRef]

6. Wu, T.; Wu, Y.C.J.; Chen, Y.J.; Goh, M. Aligning supply chain strategy with corporate environmental strategy: A contingency approach. Int. J. Prod. Econ. 2014, 147, 220-229. [CrossRef]

7. Zhang, R.; Zhang, J. Research review on sustainable supply chain management. Ecol. Econ. 2012, 1, 90-93, 97.

8. Ji, G.; Gunasekaran, A.; Yang, G. Constructing sustainable supply chain under double environmental medium regulations. Int. J. Prod. Econ. 2014, 147, 211-219. [CrossRef]

9. Tayyab, M.; Jemai, J.; Lim, H.; Sarkar, B. A sustainable development framework for a cleaner multi-item multi-stage textile production system with a process improvement initiative. J. Clean. Prod. 2020, 246, 119055. [CrossRef]

10. Hossain, M.M.; Chowdury, M.H.; Evans, R.; Lema, A.C. The relationship between corporate social responsibility and corporate financial performance: Evidence from a developing country. Corp. Ownersh. Control 2015, 12, 474-487. [CrossRef]

11. Li, Y.; Dai, J.; Cui, L. The impact of digital technologies on economic and environmental performance in the context of industry 4.0: A moderated mediation model. Int. J. Prod. Econ. 2020, 229, 107777. [CrossRef]

12. Frank, A.G.; Dalenogare, L.S.; Ayala, N.F. Industry 4.0 technologies: Implementation patterns in manufacturing companies. Int. J. Prod. Econ. 2019, 210, 15-26. [CrossRef]

13. Hosseini, S.; Ivanov, D. A new resilience measure for supply networks with the ripple effect considerations: A bayesian network approach. Ann. Oper. Res. 2019. [CrossRef]

14. Ben-Daya, M.; Hassini, E.; Bahroun, Z. Internet of things and supply chain management: A literature review. Int. J. Prod. Res. 2017, 11, 1-24. [CrossRef]

15. Sarkis, J.; Cohen, M.J.; Dewick, P.; Schröder, P. A brave new world: Lessons from the COVID-19 pandemic for transitioning to sustainable supply and production. Resour. Conserv. Recycl. 2020, 159, 104894. [CrossRef] [PubMed]

16. Ramanathan, U.; Gunasekaran, A. Supply chain collaboration: Impact of success in long-term partnerships. Int. J. Prod. Econ. 2014, 147, 252-259. [CrossRef]

17. Blome, C.; Schoenherr, T.; Eckstein, D. The impact of knowledge transfer and complexity on supply chain flexibility: A knowledgebased view. Int. J. Prod. Econ. 2014, 147, 307-316. [CrossRef]

18. Sreedevi, R.; Saranga, H. Uncertainty and supply chain risk: The moderating role of supply chain flexibility in risk mitigation. Int. J. Prod. Econ. 2017, 193, 332-342. [CrossRef]

19. Eckstein, D.; Goellner, M.; Blome, C.; Henke, M. The performance impact of supply chain agility and supply chain adaptability: The moderating effect of product complexity. Int. J. Prod. Res. 2015, 53, 3028-3046. [CrossRef]

20. Slack, N. The flexibility of manufacturing systems. Int. J. Oper. Prod. Manag. 2005, 25, 1190-1200. [CrossRef]

21. Li, G.; Ma, S.-H. Research on Flexibility Value of Enterprise's Logistics Capability in Decentralized Supply Chain. J. Manag. Sci. 2009, 22, 40-48.

22. Gosling, J.; Purvis, L.; Nairn, M.M. Supply chain flexibility as a determinant of supplier selection. Int. J. Prod. Econ. 2010, 128, 11-21. [CrossRef]

23. Rojo, A.; Llorens-Montes, J.; Perez-Arostegui, M.N. The impact of ambidexterity on supply chain flexibility fit. Supply Chain Manag 2016, 21, 433-452. [CrossRef]

24. Liu, T.; Zhong, F.S. Study on the flexibility of supply chain which based on knowledge sharing and knowledge innovation. J. Xiangtan Univ. 2012, 36, 65-68.

25. Sabri, E.H.; Beamon, B.M. A multi-objective approach to simultaneous strategic and operational planning in supply chain design. Omega 2000, 28, 581-598. [CrossRef]

26. Duclos, L.K.; Vokurka, R.J.; Lummus, R.R. A conceptual model of supply chain flexibility. Ind. Manag. Data Syst. 2003, 103, 446-456. [CrossRef]

27. Meng, J.; Zhang, R. The Comprehensive Appraisal System of Supply Chain Flexibility. China Manag. Inf. 2007, 114, 56-59.

28. Boone, C.A.; Drake, J.R.; Bohler, J.A.; Craighead, C.W. Supply chain management technology: A review of empirical literature and research agenda. Int. J. Integr. Supply Manag. 2007, 3, 105. [CrossRef]

29. Zhang, F.; Ren, S.; Yin, X. Industrial Agglomeration, Technological Innovation and Green Supply Chain Efficiency: PVAR Analysis Based on Panel Data of 28 Large and Medium-sized Steel Enterprises. Forum Sci. Technol. China 2020, 36, 51-64.

30. Li, T.C.; Lin, Q.; Ping, Y. Function mechanism of supply chain inter-firm trust on supply chain enterprises organizational improvisation: Based on study of supply chain flexibility and transitive memory system. Nankai Bus. Rev. 2018, 21, 74-84.

31. Wenqian, L.I.; Liu, Y. Technology innovation, corporate social responsibility and corporate competence:an empirical analysis based on data from listed companies. Sci. Sci. Manag. 2017, 38, 154-165. 
32. Jiao, H.; Wei, J.; Cui, Y. Path Analysis of Dynamic Capability Construction: Based on the Perspective of Entrepreneurship Orientation and Organizational Learning. Manag. World 2008, 4, 91-106. [CrossRef]

33. Krogh, G.V.; Nonaka, I.; Rechsteiner, L. Leadership in organizational knowledge creation: A review and framework. J. Manag. Stud. 2012, 49, 240-277. [CrossRef]

34. Manthou, V.; Vlachopoulou, M.; Folinas, D. Virtual e-chain (vec) model for supply chain collaboration. Int. J. Prod. Econ. 2004, 87, 241-250. [CrossRef]

35. Stank, T.P.; Keller, S.B.; Daugherty, P.J. Supply chain collaboration and logistical service performance. J. Bus. Logist. 2011, 22, 29-48. [CrossRef]

36. Eseryel, U.Y. IT-enabled Knowledge Creation for Open Innovation. J. Assoc. Inf. Syst. 2014, 15, 805-834. [CrossRef]

37. Lin, Y.H.; Tseng, M.L. Assessing the competitive priorities within sustainable supply chain management under uncertainty. J. Clean. Prod. 2016, 112, 2133-2144. [CrossRef]

38. Seok, H.; Nof, S.Y.; Filip, F.G. Sustainability decision support system based on collaborative control theory. Annu. Rev. Control 2012, 36, 85-100. [CrossRef]

39. Marchese, D.; Reynolds, E.; Bates, M.E.; Morgan, H.; Clark, S.S.; Linkov, I. Resilience and sustainability: Similarities and differences in environmental management applications. Sci. Total Environ. 2017, 613, 1275-1283. [CrossRef] [PubMed]

40. Ruiz-Benitez, R.; López, C.; Real, J.C. Achieving sustainability through the lean and resilient management of the supply chain. Int. J. Phys. Distrib. Logist. Manag. 2019, 2, 122-155. [CrossRef]

41. Sheng, S.; Zhou, K.Z.; Li, J.J. The effects of business and political ties on firm performance: Evidence from china. J. Mark. 2011, 75, 1-15. [CrossRef]

42. Long, Y.; Zhou, J. Collaborative competence in supply chain technological innovation and its effects. Soft Sci. $2015,29,47-52$.

43. Merschmann, U.; Thonemann, U.W. Supply chain flexibility, uncertainty and firm performance: An empirical analysis of german manufacturing firms. Int. J. Prod. Econ. 2011, 130, 43-53. [CrossRef]

44. Chang, A.Y. Prioritising the types of manufacturing flexibility in an uncertain environment. Int. J. Prod. Res. 2012, 50, $2133-2149$. [CrossRef]

45. Vickery, S.; Calantone, R.; Droge, C. Supply chain flexibility: An empirical study. J. Supply Chain. Manag. 2010, 35, 16-24. [CrossRef]

46. Wang, R.; Dong, M.; Hou, W. Evaluation Model and Method of Digital Maturity of Manufacturing Enterprises. Sci. Technol. Manag. Res. 2019, 39, 57-64.

47. Elkington, J. Cannibals with forks: The triple bottom line of 21st century business. Environ. Q. Manag. 1998, 8, 37-51. [CrossRef]

48. Ahmed, W.; Sarkar, B. Impact of carbon emissions in a sustainable supply chain management for a second generation biofuel. J. Clean. Prod. 2018, 186, 807-820. [CrossRef]

49. Shaharudin, M.S.; Fernando, Y.; Jabbour, C.J.C.; Sroufe, R.; Jasmi, M.F.A. Past, present, and future low carbon supply chain management: A content review using social network analysis. J. Clean. Prod. 2019, 218, 629-643. [CrossRef]

50. Mishra, U.; Wu, J.Z.; Sarkar, B. Optimum sustainable inventory management with backorder and deterioration under controllable carbon emissions. J. Clean. Prod. 2021, 279, 123699. [CrossRef]

51. Sroufe, R.; Gopalakrishna-Remani, V. Management, social sustainability, reputation, and financial performance relationships: An empirical examination of U.S. firms. Organ. Environ. 2019, 32, 331-362. [CrossRef]

52. Lee, J.; Kim, S.; Lee, S.Y. Sustainable Supply Chain Capabilities: Accumulation, Strategic Types and Performance. Sustainability 2016, 6, 503. [CrossRef]

53. Lau, R.S.; Cheung, G.W. Estimating and comparing specific mediation effects in complex latent variable models. Organ. Res. Methods 2012, 15, 3-16. [CrossRef]

54. Zhang, H.; Kang, F. Multiple Mediating Effect Analysis Method Based on Bootstrap. Stat. Decis. 2016, 5, 75-78.

55. Jie, F.; Wen, Z.; Zhang, M.; Sun, P. The analyses of multiple mediation effects based on structural equation modeling. J. Psychol. Sci. 2014, 37, 735-741. [CrossRef]

56. Podsakoff, P.M.; Mackenzie, S.B.; Lee, J.Y.; Podsakoff, N.P. Common method biases in behavioral research: A critical review of the literature and recommended remedies. J. Appl. Psychol. 2003, 88, 879-903. [CrossRef]

57. Bagozzi, R.P. Evaluating structural equation models with unobservable variables and measurement error: A comment. J. Mark. Res. 1981, 18, 375-381. [CrossRef]

58. Araz, O.M.; Choi, T.; Olson, D.L.; Salman, F.S. Data analytics for operational risk management. Decis. Sci. 2020, 51, 1316-1319. [CrossRef]

59. Ivanov, D. Predicting the impacts of epidemic outbreaks on global supply chains: A simulation-based analysis on the coronavirus outbreak (covid-19/sars-cov-2) case. Transp. Res. Part E Logist. Transp. Rev. 2020, 136, 101922. [CrossRef]

60. Craighead, C.W.; Blackhurst, J.; Rungtusanatham, M.J.; Handfield, R.B. The severity of supply chain disruptions: Design characteristics and mitigation capabilities. Decis. Sci. 2007, 38, 131-156. [CrossRef]

61. Ho, W.; Zheng, T.; Yildiz, H.; Talluri, S. Supply chain risk management: A literature review. Int. J. Prod. Res. 2015, 53, 5031-5069. [CrossRef]

62. Liu, M.; Guo, L.; Qi, Y. Flexibility value of node enterprises logistics capability in decentralized supply chain. J. Converg. Inf. Technol. 2012, 7, 270-278. [CrossRef]

63. Gunasekaran, A.; Hong, P.; Fujimoto, T. Building supply chain system capabilities in the age of global complexity: Emerging theories and practices. Int. J. Prod. Econ. 2014, 147, 189-197. [CrossRef] 